\title{
Los jóvenes en riesgo: un análisis de las percepciones sociales en la Zona 6 de Ciudad Sandino
}

\author{
Sergio José Hernández Briceño
}

\section{Resumen}

El presente artículo surge como parte de los resultados obtenidos durante el diagnóstico investigativo realizado en el 2014 en la Zona 6 de Ciudad Sandino, titulado "Inserción social de los jóvenes en riesgo". En la que se comprobó la discordancia social existente al distinguir categorías juveniles como: jóvenes en riesgo y jóvenes delictivos. Siendo una repercusión de esta contrariedad la formación de estereotipos sociales negativos acerca de la identidad del joven en riesgo, lo que se contrapone a las perspectivas institucionales y a su vez al tipo de identidad que los mismos jóvenes en riesgo de la Zona 6 han adoptado.

El propósito de este artículo investigativo es entender quiénes son realmente los jóvenes en riesgo y comprender la manera en la que toda esta serie de juicios y criterios en conjunto afectan a las identidades juveniles. El tema ha sido abordado desde el enfoque holístico- antropológico, con sus métodos y técnicas propias como la etnografía, la observación directa y participante, las entrevistas abiertas y a profundidad.

Palabras claves: Jóvenes en riesgo, Jóvenes delictivos, percepción social, Participación, Seguridad ciudadana.

\section{Abstract}

The present article began from the results during the research diagnostic made in 2014 at Ciudad Sandino's 6 th zone. The research title's was "Social insertion of youths in risk". In this research, comprove the social discordance about the social categorize of this young boys in risk as burglars.

This provoque negatives stereotypes about the youth's identities, and the young boys in the zone take this social construction about the identities, and assume as theirs.

To approach an anthropology view and different methods that converges in this research, as the ethnographic method, to take a human and holistic analysis about the perceptions in order to understand who this young people really are. Also understand the fact about how the social judgment attend against the youth's identities in a negative way.

Key words: Criminal young people, Young people in risk, social perception, Participation, Civil Security. 


\section{Introducción}

Ciudad Sandino es un espacio popularmente considerado de alto riesgo social en el departamento de Managua y tomando en cuenta que el riesgo social no es ajeno a ningún espacio habitable, es necesario destacar el grado de afectación de esta inseguridad hacia actores más vulnerables, siendo ejemplo de ello los miembros del sector juvenil.

La vulnerabilidad de los sectores juveniles es objeto de interés para Ciudad Sandino, cuya Ordenanza Municipal 061 lo destaca como un Municipio de juventudes (Ordenanza, 2010), precisamente por la fluencia de este sector en el contexto de estudio, siendo el aprovechamiento o mala orientación del potencial juvenil un factor incidente en las estrategias de desarrollo humano integral en los ámbitos sociales, políticos y económicos.

Los jóvenes en riesgo de la zona 6 en Ciudad Sandino están sometidos a diversas percepciones sociales e institucionales que surgen como parte de un análisis realizado sobre sus modos de vida y comportamientos desde donde emanan etiquetas sociales para dirigirse a estos actores como: vago, pandillero, delincuente, pinta, marginados sociales, jóvenes en riesgo.

La serie de juicios y designaciones negativas sobre los jóvenes en riesgo tienen sus repercusiones en los procesos de reinserción social y desarrollo comunitario integral; donde algunos actores juveniles terminan asumiendo gradualmente una identidad cuya principal característica es contradecir lo socialmente aceptado.

El comportamiento de los jóvenes en situaciones de riesgo responde a un sistema educativo que parte desde las estructuras nucleares familiares, hasta un conglomerado social más amplio, donde el joven se ve influenciado por elementos negativos como el déficit de atención familiar, inadecuadas relaciones interpersonales e indiferencia comunitaria hacia el proceder de estos sujetos juveniles.

La juventud en si misma representa un sector poblacional complejo y amplio para el que hacer de estudio antropológico: por ello la antropóloga Rossana Reguillo define la etiqueta de joven como "una categoría construida culturalmente..." (Reguillo,
2000, pág. 2). Aspecto retomado para la investigación debido a que el joven responde a su contexto de desarrollo sociocultural desde donde extrae elementos para su formación personal e identitaria.

\section{Metodología}

El estudio de las percepciones sociales de los jóvenes en riesgo deriva del desarrollo de un proceso investigativo exhaustivo en la zona 6 del municipio de Ciudad Sandino durante los años 2013 y 2014 en cuyos datos se lograron identificar elementos que aportan a las identidades de los mismos jóvenes desde diversas perspectivas institucionales, familiares, sociales incluyéndose en esta última instancia la autopercepción juvenil.

Para desarrollar el presente artículo se hizo uso del método etnográfico y de las técnicas propias de la investigación antropológica. El método etnográfico "consiste en descripciones detalladas de situaciones, eventos, personas, interacciones y comportamientos que son observables" (González, 2003). Siendo de gran utilidad para un proceso descriptivo y consecuente análisis de la realidad actual de las y los jóvenes, quienes llevan a cabo diversas actividades desde los espacios que habitan con fines de incidir y obtener el protagonismo necesario para lograr su desarrollo humano integral.

De igual manera se aplicó la técnica de observación directa, definida por Marshall y Rossman (1989) como aquella que "consiste en la descripción sistemática de evento, comportamiento y artefactos en el escenario social elegido para ser estudiado" (Marshall, 1989, pág. 7). Al emplear esta técnica se contempló el comportamiento de los jóvenes en riesgo durante sus reuniones o tertulias en las esquinas de la zona de estudio, sus sesiones de juegos en el parque del contexto, así como rasgos relacionados a su vestimenta, jerga e inclusive símbolos de arte urbano corporal tales como los tatuajes.

Se empleó la técnica de entrevistas abiertas y a profundidad dirigida a actores sociales, institucionales y juveniles. Los criterios de selección en el caso de los representantes de las instituciones fueron básicamente dos: la experiencia en trabajos con las juventudes del contexto comunitario así como la residencia en la 
zona de estudio, retomando para el presente artículo una muestra de ocho informantes con estas características.

En el caso de las entrevistas dirigidas a jóvenes fueron seleccionados para la investigación una muestra estadística de 8 actores juveniles, quienes habitaban en la zona 6 y estaban inmersos en situaciones de riesgo social como deserción escolar, ociosidad, integración en pandillas juveniles, entre otros.

Al mismo tiempo se tomaron a consideración espacios de conversación de carácter informal que dieron aportes a que se desarrollara un ambiente de mayor confianza y consecuente eficiencia investigativa con los mismos grupos juveniles quienes brindaron aportes en función de otorgar mayor calidad al presente estudio.

Así mismo se aplicó la investigación documental para aportar elementos al escrito, realizando para ello la revisión de fuentes bibliográficas que dieron insumos para desarrollar los antecedentes de investigación y las pautas para el análisis y profundización del tema.

\section{Antecedentes}

El primer antecedente deriva de escenarios internacionales, donde según un estudio de la Organización del Banco Mundial en América Latina "Uno de cada cinco jóvenes entre 15 y 24 años en América Latina no van a la escuela ni trabaja, es decir más de 20 millones de personas entre 15 y 24 años de edad" (Bnaco Mundial, 2016). Los efectos de un crecimiento del sector de jóvenes denominados Nini (quienes ni estudian ni trabajan) repercuten en las dimensiones políticas, sociales, económicas.

Al mismo tiempo el aumento en el sector Nini termina afectando la transición demográfica, gestando un escenario intergeneracional de desigualdad y en algunos casos fomentando los factores de violencia y delincuencia. Además hablar de jóvenes Nini en escenarios latinoamericanos es sinónimo de hablar de jóvenes en riesgo en contextos nacionales, por ello es importante analizar dicho referente.

Existen dos antecedentes nacionales a considerar para el presente artículo científico sobre todo por el hecho de que ambos escritos se realizaron durante la década de los años 90, etapa histórica en que las dinámicas políticas y socioeconómicas del país llevaron a una alta tasa de desempleo, que dio paso a un apogeo del fenómeno pandilleril en nuestra nación. Hay que mencionar que los grupos juveniles empezaron a ser parte de un complejo fenómeno de marginalización y exclusión social, que repercutió en una creciente inseguridad social y aumento de los niveles delictivos. Fenómeno interpretable como consecuencia de las políticas neoliberales de privatización de los servicios básicos, que se aplicaron en Nicaragua después de las elecciones del 1990, con el propósito de desarticular el modelo social y económico de equidad y emancipación que la experiencia revolucionaria sandinista había impulsado a lo largo de los 80 .

Una de estas investigaciones sobre el fenómeno de las pandillas es la realizada por el antropólogo Dennis Rodgers, titulada "Un antropólogo pandillero en un barrio de Managua” (Rodgers, 1997), quien estudió la estructura, ritos de iniciación, conductas de una pandilla de un barrio de Managua, para entender por medio de la técnica de observación participante el modo de vida de estos actores sociales delictivos.

Si bien es cierto el objeto de análisis en este escrito son jóvenes en riesgo y no jóvenes delictivos, retomar aspectos del estudio previamente descrito aportó en la búsqueda y análisis de similitudes entre ambos grupos juveniles.

Otro aporte a los estudios de los grupos juveniles se encuentra en la obra de Roger Matus Lazo, autor del libro El lenguaje del pandillero (obra desarrollada en diversos barrios marginados de la ciudad de Managua), quien declara la importancia de no confundir la ambivalencia entre la pobreza y la delincuencia como un rasgo homogéneo y distintivo de los actores que viven en situaciones de pobreza y marginalidad socioeconómica.

Al mismo tiempo el autor expresa que existen otros tipos de ambivalencia que no deberían de ser determinantes como la relación pandillero y delincuente, expresando lo siguiente "No todo pandillero es un ladrón o no todo ladrón es pandillero, en ocasiones habrá personas que son ambas" (Lazo, 1997). Es claro el mensaje de que no se deben crear estereotipos hacia los jóvenes cuya condición económica sea menos favorable en términos económicos; por ende es importante desvincularse de las ideas preconcebidas a fin de no perder de vista la objetividad de una investigación de este tipo. 
De igual forma se tomó en cuenta algunos registros sobre proyectos en beneficio de la juventud que fueron llevados a cabo en Ciudad Sandino, ejemplo son las propuestas políticas de reinserción social juvenil impulsadas durante el gobierno de Enrique Bolaños Guillén en el año 2005, por medio de la Fundación Nicaragua en base al Proyecto "Apoyo y Fortalecimiento de la Seguridad Ciudadana", con la colaboración del PNUD y la Policía del Municipio de Ciudad Sandino, quienes trabajaron en la reinserción social y laboral de 10 pandillas conformadas por 175 jóvenes y adolescentes a quienes se les impartieron cursos técnicos para el fomento de sus habilidades y generación de ingresos monetarios. El proyecto duró tres meses y durante este proceso los jóvenes optaron por una forma de vida alterna beneficiosa para el progreso en sus vidas.

Otro antecedente importante en el presente estudio es la "Ordenanza Municipal 061 de Ciudad Sandino", aprobada el 10 de septiembre del 2010, esta ordenanza incluye la creación de un Departamento de la Juventud dentro de la Comuna, que es parte de la propuesta presentada por los jóvenes organizados de Ciudad Sandino, en el Departamento de Managua" (LA PRENSA, 2010). Esta ordenanza jurídica promueve el reconocimiento que se le da al municipio de Ciudad Sandino como un lugar de juventudes y al mismo tiempo evidencia la pertinencia investigativa del presente estudio.

Previo a desarrollar los resultados del presente artículo se hará énfasis en relación a la categoría de "riesgo" la que si bien es cierto representa una variable amplia; en esta ocasión se delimita al tipo de "riesgo social" que se ven expuestos los jóvenes de convertirse en actores delictivos, representando de este modo un factor de inseguridad ciudadana para sí mismo y para el resto de la comunidad.

La caracterización institucional y social sobre el joven en riesgo colisiona con el sentir auto identitario de los mismos actores juveniles, pero al mismo tiempo la abastecen. Ejemplo de esta circunstancia se da al momento en que los grupos en riesgo social se declaran diferentes a los actores delictivos a pesar de compartir símbolos o espacios, haciéndose notar como actores juveniles sin intenciones de afectar negativamente a la sociedad.

\section{Resultados}

Previo a desarrollar los resultados del presente artículo se hará énfasis en relación a la categoría de "riesgo" la que si bien es cierto representa una variable amplia; en esta ocasión se delimita al tipo de "riesgo social" que se ven expuestos los jóvenes de convertirse en actores delictivos, representando de este modo un factor de inseguridad ciudadana para sí mismo y para el resto de la comunidad.

La caracterización institucional y social sobre el joven en riesgo colisiona con el sentir auto identitario de los mismos actores juveniles, pero al mismo tiempo la abastecen. Ejemplo de esta circunstancia se da al momento en que los grupos en riesgo social se declaran diferentes a los actores delictivos a pesar de compartir símbolos o espacios, haciéndose notar como actores juveniles sin intenciones de afectar negativamente a la sociedad.

\section{Caracterización de los jóvenes en riesgo}

Según datos del Instituto Nacional de Información de Desarrollo (INIDE) "Nicaragua es un país de jóvenes, donde el $70 \%$ de la población es menor de 30 años" (INIDE, 2006). En vista de que este segmento social representa la mayoría poblacional del país, es necesario visualizarlo como potencial para trazar la meta hacia un desarrollo humano integral; sin embargo para lograrlo es necesario erradicar estereotipos negativos que la misma sociedad tiene sobre aquellos jóvenes que representan un sector poblacional inmerso en circunstancias de vulnerabilidad social.

Dichos jóvenes en circunstancias de vulnerabilidad social, denominados por las instituciones jóvenes en riesgo, tienen elementos en común con aquel 17\% de jóvenes Nini (PNUD, 2011), porque ellos tampoco estudian, ni trabajan. Sin embargo, los jóvenes en riesgo tienen otras características adicionales, como el uso de tatuajes, el agruparse en pandillas, ser parte de grupos abiertos en rangos de edades, estar propensos al consumo de sustancias controladas y a la consecuente práctica de violencia bajo los efectos de las mismas. 
Vale la pena hacer hincapié en que los llamados jóvenes en riesgo están inmersos en actividades pre delictivas y por tanto no se les debe confundir con actores juveniles delictivos, pese a tener elementos en común con estos y hasta relacionarse con los mismos. Abordando esta diferencia el Oficial encargado de la Dirección de Asuntos Juveniles de la Policía Nacional en Ciudad Sandino, Alan Alvarado, expresa:

"Los jóvenes en riesgo son aquellos grupos de chavalos que están aún a tiempo de ser rescatados de convertirse en delincuentes, es decir a éstos se les puede ayudar con charlas, programas de becas, capacitaciones, programas de recreación; en fin; aún es posible sacarlos de esas situaciones, puesto que ellos no han entrado en lleno a la vida delictiva" (07/06/14).

El Oficial Alvarado desde un punto de vista institucional aclara la diferencia existente del joven en riesgo con el joven delictivo; no obstante, dicha definición no es compartida por los actores comunitarios en la zona 6 , quienes no se familiarizan con la categoría institucional ni con el modo de vida del joven en riesgo.

La falta de armonía entre las percepciones sociales e institucionales sobre los jóvenes en riesgo, genera como consecuencias prejuicios sociales que convierten al joven en riesgo en un análogo del joven delictivo o comúnmente llamado pandillero, apreciación que debe ser reformada para evitar déficits en los procesos de reinserción comunitaria dirigidos a dichos jóvenes y una negativa difusión generacional sobre el modo de vida de los mismos.

\section{Diferencia entre el joven en riesgo y el actor delictivo juvenil}

Al hablar de percepciones sociales en el presente artículo no es posible obviar la autopercepción que realizan los jóvenes en riesgo; quienes no se sienten identificados con esta etiqueta social de riesgo que se les ha asignado desde la institución policiaca; considerándose simplemente jóvenes con su propio estilo de vida con el que se sienten cómodos; al mismo tiempo reconocen que la población los confunde con delincuentes, lo cual ocasiona miedo, repudio y un sentimiento de inseguridad de parte de las personas de la comunidad hacia ellos; partiendo de estas ideas y de lo observado en el proceso de investigación, vale la pena caracterizar al joven en riesgo y al joven delincuente, dando a conocer los siguientes elementos:

Existen elementos en común entre el joven en riesgo y el joven delictivo, de igual modo se encuentran leves diferencias entre uno y otro actor social siendo la principal de estas la capacidad de delinquir que desarrollan los jóvenes delictivos a diferencia de los jóvenes en riesgo.
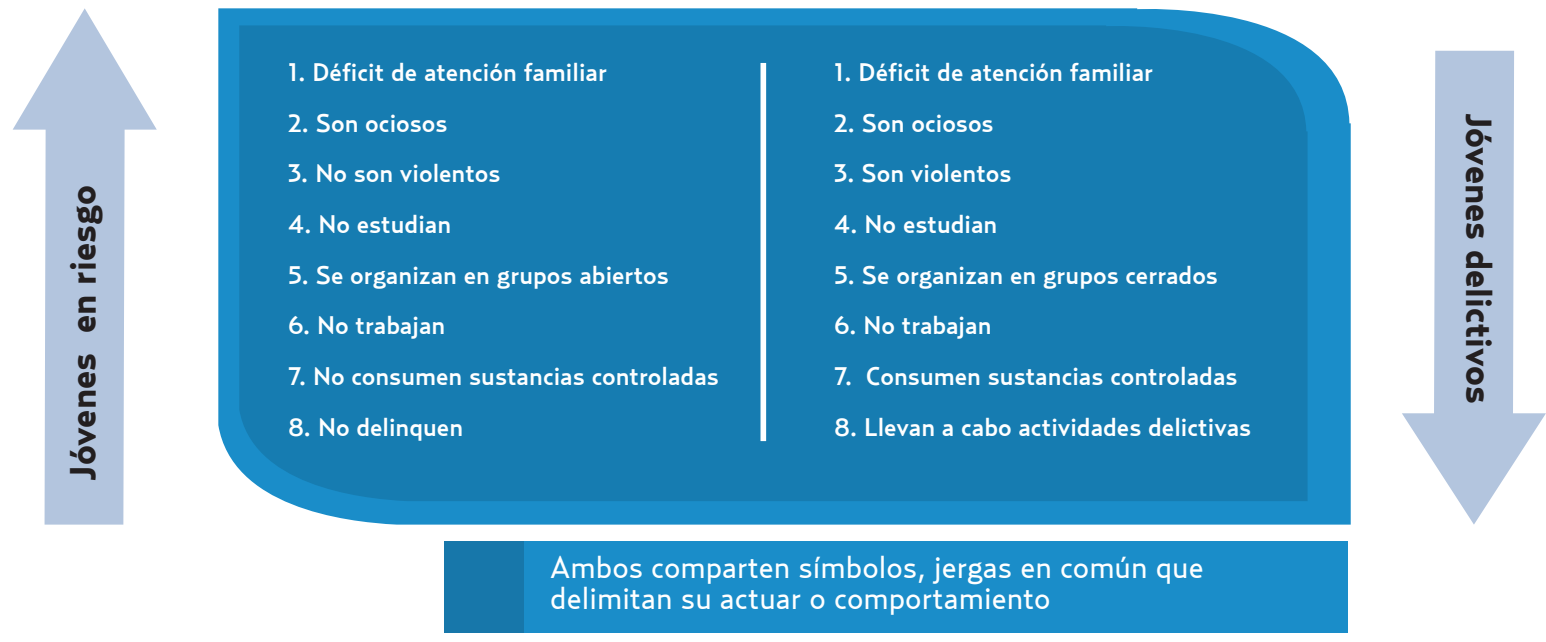

Cuadro comparativo entre jóvenes en riesgo y delictivos (Fuente propia) 
Partiendo de este punto se debe analizar el tipo de incidencia que tienen estas percepciones sociales sobre el sentir y estilo de vida de los jóvenes en riesgo, ya que estos actores están expuestos a una serie de criterios derivados de la forma en que la comunidad en general percibe sus modos de vida, conductas y comportamientos que se ven evidenciados en los espacios públicos de la zona de estudio como las calles, esquinas, parques, entre otros. La temática de percepciones sociales es extensa y compleja, por ello es importante definir el término percepción desde la disciplina antropológica; al respecto la antropóloga María Vargas expresa:

"Desde un punto de vista antropológico.....La percepción atribuye características cualitativas a los objetos o circunstancias del entorno mediante referentes que se elaboran desde sistemas culturales e ideológicos específicos construidos y reconstruidos por el grupo social, lo cual permite generar evidencias sobre la realidad." (Vargas, 1995)

En efecto a los jóvenes en riesgo se les atribuyen diversas características como la ociosidad, desinterés, peligrosidad, entre otros caracteres que terminan haciendo de estas agrupaciones en situaciones de riesgo referentes negativos en la sociedad. Por otro lado, es necesario tomar en cuenta que al hablar de jóvenes en riesgo se está ante una categoría que tiende a ser amplia, difusa o confusa y en el extremo de los casos desconocida para la sociedad en general incluyéndose los mismos jóvenes. En otras palabras las percepciones sociales que versan respecto a los jóvenes en riesgo son parte de un proceso dinámico; lo cual es reforzado por María Vargas, quien manifiesta que:

"La percepción no es un proceso lineal de estímulo y respuesta sobre un sujeto pasivo, sino que, por el contrario, están de por medio una serie de procesos en constante interacción y donde el individuo $y$ la sociedad tienen un papel activo en la conformación de percepciones particulares a cada grupo social" (Vargas, 1994, pág. 2).

Las percepciones que se desarrollan sobre los jóvenes en riesgo no son producto exclusivo de una relación lineal entre dos actores sociales (joven vs. sociedad), muchas veces sin necesidad de una interacción directa entre ambos sectores (debido a la actual indiferencia de la comunidad hacia el análisis del comportamiento de estos jóvenes) ya existen estereotipos y estigmas generacionales negativos que han sido asu- midos dentro de la población etiquetando al joven en riesgo de forma despectiva.

\section{Perspectivas institucionales sobre los grupos juveniles en situaciones de riesgo}

En el contexto de la zona 6, además de la institución policiaca, existen otras instituciones que se relaciona con la dinámica de los jóvenes en riesgo, tal es el caso del Centro de Educación y comunicación popular CANTERA, institución que proporciona al joven alternativas en distintas disciplinas y programas de tipo socioculturales por medio de las cuales logre recrearse, apartarse de las conductas delictivas y por tanto invertir su tiempo y energía en otro tipo de actividades sociales de mayor provecho. Todo esto con fines de evitar altercados como los que expresa a continuación el Oficial Alan Alvarado.

"En la Zona 6, hay bastantes pleitos y robos, especialmente en el parque, por lo que es una zona de concentración para los grupos de jóvenes en riesgo y los grupos delictivos" (07/06/14).

El Oficial Alvarado enmarca una seria problemática de inseguridad ciudadana en donde se tiene como zona de afluencia delictiva el parque de la Zona 6, sitio de estadía compartido por el joven en riesgo y el joven delincuente. Situación que aumenta las confusiones sociales acerca de delictivo que puede asumir el mismo jóven en riesgo.

El perfil institucional del Centro de Educación y comunicación popular - CANTERA se apega a la prevención de violencia impartida desde las edades de la niñez y la adolescencia. Parte del personal encargado de trabajar con las juventudes de la Zona 6 expresan su sentir y conocimiento en relación a las identidades de los jóvenes en riesgo siendo alguna de estas opiniones, la emitida por Vicente Sean, encargado del Área de Dirección de Centro de Educación y Comunicación popular - CANTERA, Zona 6 ciudad Sandino:

"Para mí los jóvenes en riesgo son aquellos que no tienen oportunidades para formarse y seguir estudiando o bien encontrar trabajos que les interesen. Son aquellos que no tienen un proyecto de vida. No tienen acompañamiento de la familia u otro mentor de quien aprender sobre sus pasiones e intereses" (26/04/15). 
Según esta percepción, el joven en riesgo es aquel que tiende a ser alguien que requiere de un acompañamiento y apoyo desde diversas dimensiones familiares y sociales con las que pueda crear alternativas de crecimiento y desarrollo personal logrando beneficiar de este modo a personas de modo directo e indirecto en aspectos de seguridad ciudadana, liderazgo social y trabajo comunitario.

Las percepciones que los miembros de la comunidad tienen sobre los jóvenes en riesgo están en correspondencia a diversos patrones y características visibles como es el portar tatuajes, elemento común en los jóvenes en riesgo y delictivos. Partiendo de los juicios que existen en relación al portar o no tatuajes se evidencia la discrepancia existente entre el pensar de la sociedad en general y el de los jóvenes en riesgo, por ello es necesario comprender que la percepción que versa sobre el uso del cuerpo repercute en la formación de juicios sociales, así lo expresa el antropólogo francés Pierre Bourdieu: "El propio cuerpo es una forma particular de experimentar la posición en el espacio social" (Bourdieu, 1986, pág. 184)

Acorde a lo que manifiesta Bourdieu, se puede interpretar la forma en la que la sociedad relaciona el portar tatuajes con la condición o cualidad antisocial y criminalista atribuida en el caso particular a un joven en riesgo. El joven con tatuajes es etiquetado no por los motivos o significados del arte en su cuerpo sino por el sentir y pensar de los demás.

El estilo de vida de los jóvenes en riesgo se convierte en sujeto de críticas desde el momento en que su pensar y actuar no coinciden con el modo de vida aceptado por la comunidad, sin embargo parece evidente que los jóvenes en riesgo no pretenden satisfacer o adecuarse a una lógica social, así lo reafirma la antropóloga Valentina Torres.

"A través del tatuaje, los jóvenes encuentran una nueva vía de expresión, un modo de alejarse de una normalidad que no les satisface... La marca les permite recuperar/apropiarse de su cuerpo que simboliza y reproduce 'la exclusión' de la que el sujeto es objeto" (Torres, 2007, pág. 5)

Si bien es cierto el realizarse tatuajes es sólo una de las características de los jóvenes en riesgo, ésta puede considerarse como producto de la falta de entendimiento entre este sector social con el resto de las personas de la comunidad, al joven no le inmuta mostrar sus tatuajes así como tampoco se inhibe de evidenciar su estilo de vida ante la población en general, esto podría considerarse una especie de auto estigmatización con la que el joven secunda las percepciones negativas que la sociedad crea sobre este; sin que esto le afectase en lo absoluto. Si bien es cierto los tatuajes dan pase a que la sociedad etiquete al joven en riesgo como delincuente, no es conveniente considerarle delincuente por aspectos superfluos como el arte urbano que representan estos símbolos.

En la temática de percepciones sociales es conveniente hacer mención de una serie de pares dicotómicos como pandillero - delincuente; joven en riesgo - joven delictivo; jóvenes vulnerados - jóvenes vulnerables; etapa delictiva - etapa pre-delictiva; etapa de riesgo - etapa post-riesgo; todo con fines de comprender la diferencia entre cada uno de ellos y de este modo comprender que es lo que realmente esta pasando con los jóvenes de ahora en nuestra sociedad ; en relación a algunos de estos pares previamente mencionados, Ana Castillo, educadora del Centro de Integración y Capacitación Maura Clarke (CECIM), considera que

"Hablar de jóvenes en riesgo, es hablar de todas $y$ todos los jóvenes que pueden ser víctima de persuasión para el consumo de sustancia; por otro lado para mí los chavalos que ya están delinquiendo son quienes ya pasaron la etapa de riesgo". (29/04/15)

Distinguir entre las etapas pre delictivas o de riesgo y la etapa delictiva o pos riesgo no es una labor sencilla y la indiferencia social que existe por tratar de distinguir entre ambas etapas termina siendo un factor que aumenta lo complejo de esta tarea. Las situaciones de riesgo a las que se ven expuestos los jóvenes representan factores que promueven la inseguridad ciudadana debido a que un joven que actualmente viva en circunstancias de riesgo, representa un próximo actor delictivo; de este modo están descuidándose actores sociales que pueden contribuir al desarrollo integral individual y comunitario de la zona de estudio.

A fin de evitar que los jóvenes estén inmersos en situaciones de riesgo como la deserción escolar, la estadía en las esquinas, las agrupaciones conflictivas o violentas, consumo de sustancias controladas, entre otros; es necesario que se lleve a cabo un acercamiento hacia estos jóvenes desde diversos actores sociales e institucionales, esto con fines de analizar el modo de vida alterno de este grupo social, el cual se contradice con la 
lógica de lo que es socialmente aceptado, positivo y útil al desarrollo comunitario integral o en otras palabras, a como lo define la antropoóloga, Roxana Reguillo:

'Los 'alternativos'o 'disidentes' cuyas prácticas culturales han producido abundantes páginas y que han sido analizados desde su no-incorporación a los esquemas de la cultura dominante" (Reguillo, 2000).

El adecuado acercamiento entre los miembros de la comunidad con los jóvenes en riesgo, permitirá que los demás actores sociales externos a los grupos juveniles, puedan diferenciar en relacion a toda una diversidad de detalles que le permitan identificar entre categorías como las de jóvenes vulnerados y jóvenes vulnerables; siendo la definición de estos según la socióloga Marielle Palau la siguiente.

"El primer segmento de jóvenes vulnerados está en correspondencia a la existencia de algún ámbito de exclusión social...provocado por un evento coyuntural; el segundo segmento de jóvenes vulnerables se refiere a los casos donde el sujeto identifica un inminente o probable riesgo social o alguna privación a futuro....pasando a engrosar el segmento de los excluidos". (Palau, 2004, pág. 24)

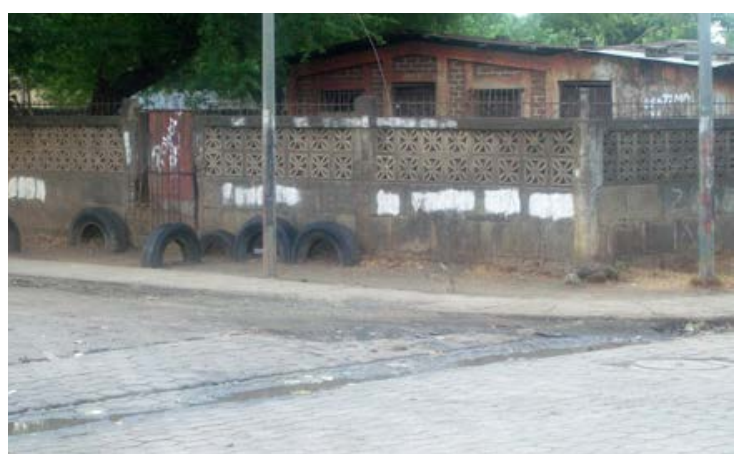

Esquina contigua al parque de la Zona 6 (Fuente propia)

Los jóvenes en proceso de exclusión social suelen encontrarse en las esquinas y en diversos puntos del parque con distintas agrupaciones juveniles cuyos horarios de reunión son más afluentes por la tarde, tiempo en el que estos jóvenes empiezan a organizarse para jugar entre ellos mismos, llevar a cabo charlas cotidianas o simplemente sentarse a observar el tránsito peatonal $\mathrm{y}$ vehicular de su alrededores. Estas agrupaciones juveniles representan grupos sociales abiertos que no se limitan a estándares de edades, sino que involucran a personas adultas tal como lo expresa Reguillo "Definir al joven en términos socioculturales implica, en primer lugar, no conformarse con las delimitaciones biológicas, como la de la edad" (Reguillo, 2000), con esto se habla de una diversidad de actores que comparten espacios en común adquiriendo un grado de significación desde las cosmovisiones y autopercepciones de los sujetos en riesgo.

\section{Percepciones, espacios y comportamiento de los jóvenes en riesgo}

La comunidad en general y los mismos jóvenes en situaciones de riesgo asignan desde sus percepciones significados a los elementos con los que se familiarizan; es decir los actores comunitarios tienen sus ideas en relación a la forma en la que los espacios de tienden a etiquetarles; ejemplo de ello es cuando un joven asiste constantemente a fiestas es considerado una persona alegre; si una persona frecuenta una biblioteca es visto como un hábil lector e inteligente; en el caso de los jóvenes en riesgo si son evidenciados recurriendo a las esquinas del sector son considerados vagos, asaltantes, drogadictos, en fin son vistos como personas peligrosas.

En otras palabras las esquinas se convierten en lo que el geógrafo Tuan considera como "El espacio limitado y humanizado. El espacio se transforma en lugar al adquirir definición y significado" (Tuan, 1977, págs. 54-136)

El significado que las esquinas de la Zona 6 adquieren para los jóvenes en riesgo, va más allá de ser simple espacios de tránsito o lo que el antropólogo Marc Augé conceptualizo como un no lugar, es decir instalación necesaria para la circulación acelerada de las personas, (Augé, 1992). De hecho los jóvenes en riesgo y la comunidad en general asignan significados a estos puntos de reunión en donde de modo cotidiano llevan a cabo rituales de convivencia e interacción y donde hacen público su estilo de vida.

La importancia de adecuar la percepción poblacional a un óptimo sistema de reinserción social dirigido al joven en riesgo radica en lo útil que esto es para dar continuidad a patrones de comportamiento antisocial y pre delictivos que son identificados en los mismos actores juveniles; por ello es de vital importancia saber que piensa la población joven acerca de los sectores de 
juveniles en riesgo; al respecto Bryan López de 17 años define a los jóvenes en riesgo de la siguiente manera

"Los jóvenes en riesgo son aquellos chavalos que nadie les quiere hablar, platicar o juntar con ellos, la gente piensan que ellos se merecen estar en una esquina y que no pasen de ahí’. (04/11/15)

Partiendo de esta cita es notoria la percepción del joven en riesgo sobre sí mismo desde la cual este actor se tiende a diferenciar entre los roles y modos de vida de un grupo juvenil delictivo ante un colectivo social; sin embargo ambos grupos juveniles terminan siendo asociados como análogos debido a diversas dinámicas como la tener espacios compartidos, mostrar comportamientos violentos, agruparse en pandillas, entre otras.

En cuanto a la formación de pandillas juveniles, es necesario destacar que estas formas de agrupación son parte de las similitudes de los jóvenes en riesgo y jóvenes delictivos debido a que este gremio se crea a partir de la dinámica de exclusión, de la que son víctimas ambos sectores juveniles. Al respecto, la socióloga y politóloga Kristina Pirker, retomando un nivel más general en ámbitos territoriales, expresa que:
"Las pandillas juveniles centroamericanas se mueven en un contexto caracterizado no solamente por las carencias socioeconómica sino por la destrucción del tejido social en tér minos culturales e intersubjetivos". (Pirker, 2004)

Claramente la expresión social que representa las pandillas dista de ser exclusiva de los sectores pauperizados estando más bien en correspondencia a elementos culturales y sociales en los que la exclusión gesta un espacio de integración entre los mismos jóvenes que se sienten marginados producto de la misma discordancia social existente entre sus ideales personales y los objetivos sociales.

Por otro lado ya sea que estamos hablando de jóvenes en riesgo o jóvenes delictivos, lo cierto es que en la zona de estudio el empleo de estas etiquetas y de muchas otras más hacen que la población se termine olvidando de que antes de ser chavalos vagos, pintas o inclusive jóvenes en riesgo, son simplemente jóvenes y que por tanto no se debe perder esta perspectiva en relación a quiénes son estos grupos de personas que por uno $\mathrm{u}$ otro motivo llámese social, económico o familiar, se encuentran en situaciones de vulnerabilidad social.

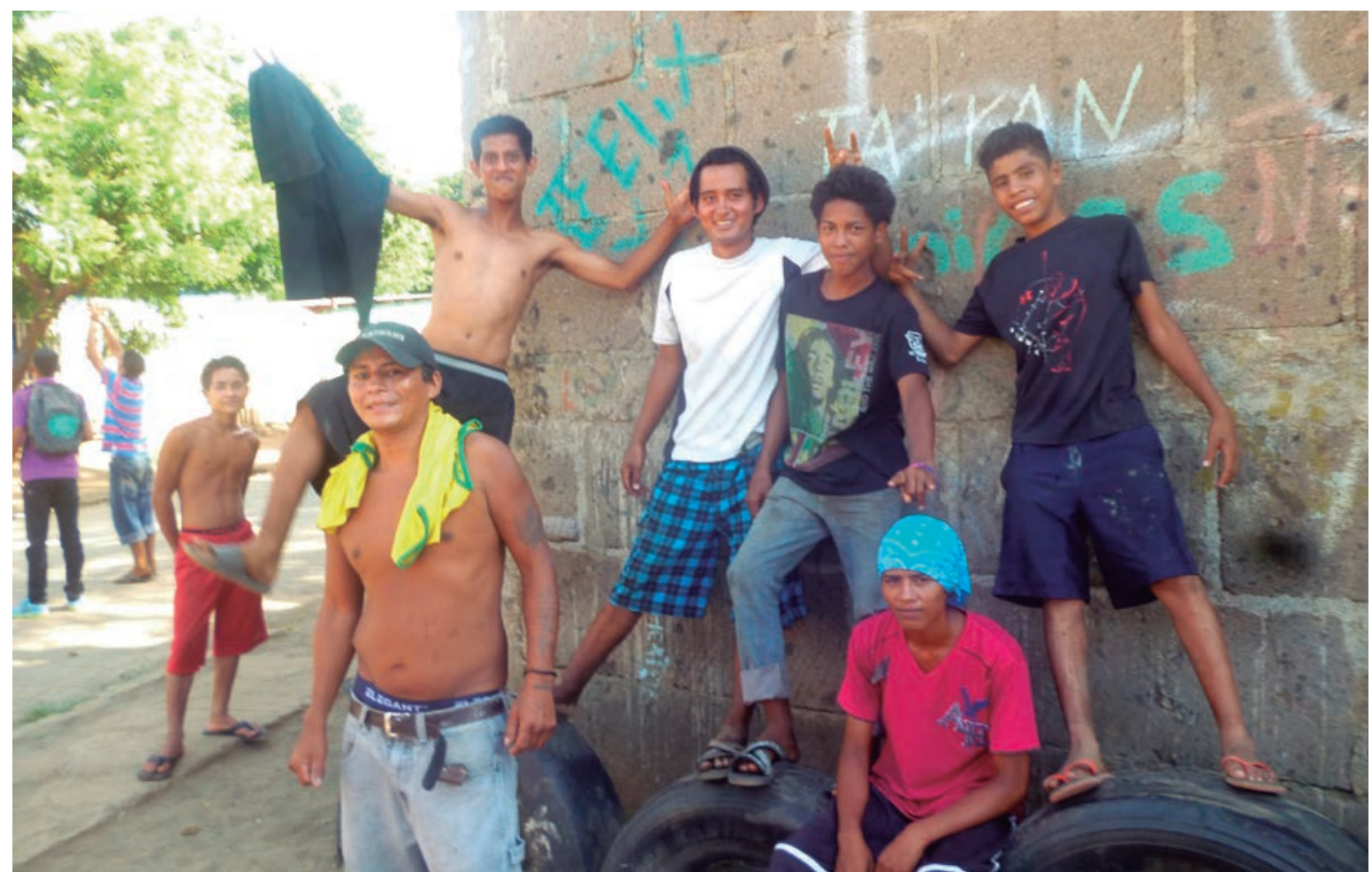

Jóvenes en situaciones de riesgo (Fuente propia) 
Hace falta reconocer a la juventud y el potencial que este representa; solo con este reconocimiento se podrá involucrar al joven en riesgo en las dinámicas de inserción y desarrollo social que logren erradicar al mismo tiempo las etiquetas sociales negativas que les han sido asignadas a estos grupos de jóvenes. Al respecto del empleo de las etiquetas de jóvenes en riesgo y de su aceptación social, Guillermo Marenco, quien trabajó con actores juveniles desde su experiencia en la institución CANTERA de Ciudad Sandino, expresa:

“Por qué etiquetar a los jóvenes?... Eso es lo que se hace la policía pero para mí solo debería ser un concepto para una estrategia de seguridad ciudadana o algo así y no para catalogar o señalar a la juventud (12/05/15)

El informante critica la categoría asignada a este grupo de jóvenes en circunstancias de vulnerabilidad social, ya que con ello se está obviando la percepción del joven hacia su propia situación, la no apropiación de la categoría de jóvenes en riesgo desde los mismos jóvenes, representa no solo un conflicto acerca del uso inapropiado término,

sino también un disturbio desde la forma en la que se contempla un modo de vida juvenil.

El modo de vida de un joven en situación de vulnerabilidad se asocia a la categoría de jóvenes en riesgo, esta designación responde más a un criterio de selección y estudio policiaco tal como lo expresa el informante y se emplea al margen de las identidades de estos grupos juveniles, convirtiéndose de este modo en una etiqueta hasta negativa para estos jóvenes. Así lo reafirma el informante Marenco al relatar una de sus experiencias acontecidas:

"En algún momento esa categoría (jóvenes en riesgo) nos etiquetaba y nosotros nos sentíamos discriminados primero porque éramos de Ciudad Sandino, llegábamos a otro lugar y decían los jóvenes en riesgo de Ciudad Sandino y todo mundo se corría entrabamos al auditorio y se iban y quedábamos solo los de Ciudad Sandino, te estoy hablando hace mucho tiempo y aún sigue la categoría, no ha evolucionado, ese concepto seguimos viendo al chavalo como el problema y no como el potencial" (12/05/15)

\section{Discusión de Resultados}

Los jóvenes en riesgo representan la cara de un sector social vulnerable y sumamente importante para el desarrollo del país, por ello es necesario el adecuado acercamiento y apoyo desde cada espacio comunitario hacia estos sectores juveniles.

Las categorías institucionales dirigidas a la juventud en situaciones de riesgo es útil y eficaz para los planes y propuestas de estos entes, no obstante dichos calificativos distan de una cercanía popular con estos jóvenes a los que se les quiere apoyar para tener mejores opciones de desarrollo integral.

La antropóloga Rosana Reguillo considera que los jóvenes han sido estudiados desde su no integración a la cultura dominante. A partir de los datos recopilados en la presente investigación, los sectores juveniles son estudiados no sólo desde un enfoque de indiferencia o margen social, sino también desde un aspecto identitario, resultante desde esa misma inadaptación social, temporánea en caso de que exista un acercamiento adecuado hacia estos sectores sociales.

El hecho de estudiar al joven más allá de su condición biológica es una propuesta que también brinda la investigadora Reguillo, postura secundada desde los resultados del presente estudio, donde se analizó al joven a partir de su dinámica cultural, tomando en cuenta las percepciones y re significaciones elaboradas en torno a su entorno social y no su condición fisiológica.

La destrucción del tejido social es la razón según Kristina Pirker para la formación de pandillas centroamericanas, sin embargo las afectaciones negativas de un nivel macro social no son un factor exclusivo en la formación de patrones de comportamientos pre delictivos y delictivos, también la situación micro social tiene su grado de influencia como los déficits de atención familiar, ociosidad, consecuente libertinaje y adopción de conductas vandálicas que con el tiempo se acrecientan y consolidad.

La autora Marielle Palau hace una distinción entre jóvenes vulnerados y jóvenes vulnerables, distinción análoga a los sectores juveniles marginados y en situaciones de riesgo; ambas etapas que marcan la pauta para diferenciar el tipo de acercamiento que se debe tener con cada uno de estos actores; en el caso de los jóvenes vulnerables o en riesgo se trata de prevenir una exclusión a futuro de la comunidad de parte hacia estos actores.

Transformar los espacios de un no lugar a un lugar es posible, según Marc Augé, por medio de la re-signifi- 
nificación que los actores (en este caso los jóvenes) les dan a espacios de tránsito peatonal. Tras el estudio realizado a los sectores juveniles en Ciudad Sandino, se confirma esta postura, debido a que las esquinas, callejones, aceras se transforman en espacios marcados de interacción colectiva juvenil; observatorios peatonales sociales cuya funcionalidad yacen en ambas direcciones, donde los jóvenes observan el resto de la comunidad y al mismo tiempo son observados.

\section{Conclusiones}

El término de jóvenes en riesgo representa una categoría institucional empleada por entes como la Dirección de Asuntos Juveniles de la Policía Nacional, CANTERA, CECIM en la Zona 6 de Ciudad Sandino, para diferenciar a los jóvenes con comportamiento pre-delictivo de los que ya están delinquiendo.

El sector comunitario y juvenil afirman desconocimiento hacia la referencia que representa la categoría jóvenes en riesgo, mostrándose indiferente ante su uso y empleando otros calificativos que asocian más al joven hacia una dinámica de exclusión como por ejemplo: pandillero o marginado social.

Muchas de las percepciones sociales existente sobre los jóvenes residen en la diferenciación hacia una serie de pares dicotómicos entre las que destacan: pandillero - delincuente; joven en riesgo - joven delictivo; jóvenes vulnerados - jóvenes vulnerables; etapa delictiva - etapa pre-delictiva; etapa de riesgo - etapa post-riesgo; todas categorías que permitirán comprender la situación por la que están pasando los jóvenes de ahora en la sociedad.

La comunidad en general tiende a confundir al joven en riesgo con el actor delictivo, esto producto de los estereotipos negativos transmitidos de modo generacional que limitan una participación ciudadana masiva que contribuya a la inserción social de estos jóvenes vulnerables, eliminando de este modo futuros sectores sociales excluidos o marginados.

Es necesario visualizar al llamado joven en riesgo, como un actor social capaz y apto para la toma de decisiones que aporten al bienestar local y nacional, se requieren mayores inversiones en evitar acrecentar los sectores marginados, apoyando al joven en riesgo hacia una reinserción adecuada y efectiva al seno de la sociedad.

\section{Referencias Bibliográficas}

Augé, M. (1992). Los no lugares, espacios del anonimato. Barcelona: Gedisa.

Bourdieu, P. (1986). Notas provisionales sobre la percepción social del cuerpo. Madrid-España: La piqueta.

González, J. y. (2003). Paradigmas Emergentes Y Métodos De Investigación en el Campo de la Orientación.

Instituto Nacional de Información de Desarrollo, (2006). Anuario Estadístico 2006. Managua-Nicaragua: Anuario Estadístico.

LA PRENSA. (10 de 09 de 2010). Ciudad Sandino, municipio de la juventud. LA PRENSA, pág. 1.

Lazo, R. M. (1997). El lenguaje del pandillero. Managua: Centro de investigación de la realidad de América Latina.

Marshall, C. \&. (1989). Designing qualitative research. Newbury: Park, CA: Sage.

Melgarejo, L. M. (1994). Sobre el concepto de percepción. ALTERIDADES, 47-53.

Mundial, Banco. (2016). Ninis en América Latina. Washington DC: Grupo Banco Mundial. Obtenido de https://openknowledge.worldbank.org/bitstream/ handle $/ 10986 / 22349 / \mathrm{K} 8423$.pdf? sequence $=5$

Ordenanza municipal 061 emitida el 10 de septiembre del 2010, http://www.laprensa.com.ni/2010/09/14/nacionales/466676-ciudad-sandino-municipio-de-la-juventud.

Palau, M. (2004). Resultados del estudio "juventud y exclusión social" : conceptos, hipótesis y conocimientos interpretativos de la condición juvenil. Asuncion-Paraguay: BASE invesigaciones sociales CLACSO.

Pirker, K. (2004). Sujetos, víctimas y territorios de la violencia en America Latina. Mexico: Universidad de la ciudad de Mexico.

PNUD (Dirección). (2011). Documental Informe del Desarrollo humano Juventudes en Nicaragua [Película]. 
Reguillo, R. (2000). Las culturas juveniles: un campo de estudio; breve agenda para la discusión $n^{\star}$. Guadalajara: Departamento de Estudios de la Comunicación Social Instituto Tecnológico de Estudos Superiores do Ocidente, Departamento de Estudios Socioculturales.

Rodgers, D. (23 de Julio de 1997). Envío Digital. Obtenido de http://www.envio. org.ni/articulo/305

Torres, V. (2007). Utilizando el cuerpo, una mirada antropológica al tatuaje. Montevideo.

Tuan, Y.-F. (1977). Lugar y espacio: una perspectiva de la experiencia. Minessota: Minneapolis.

Vargas, L. M. (1995). Los colores lacandones: un estudio sobre percepción visual. Mexico: Escuela Nacional de Antropología e Historia. 